\title{
Gorilla auf den Augen
}

In einem berühmten Experiment zeigten Daniel J. Simons und Christopher F. Chabris Probanden kurze Filme eines Ballspiels. Die Probanden sollten zählen, wie häufig eines von zwei Teams den Ball passte.

Der Clou: Während des Spiels lief eine Frau in einem Gorilla-Kostüm von einer Seite des Spielfelds zur anderen, mitten durch die Spieler hindurch. Im Nachhinein befragt, hatte gut die Hälfte der Probanden keinen Gorilla gesehen. Das kann auch Experten passieren: Auf der Suche nach Krebsanzeichen übersahen 20 von 24 Radiologen einen Streichholzschachtel-großen Gorilla, den die Forscher als Hommage an Simons und Chabris in Schnittbilder der Lunge montiert hatten [Drew T et al. Psychol Sci. 2013;24(9):1848-53]. Das spreche nicht gegen Radiologen, sondern für die begrenzte Wahrnehmung des Menschen, so die Forscher: Wer auf einen spezifischen Zielreiz achtet, wird andere Reize eher übersehen.

Moritz Borchers

Wie wird das Phänomen in der Literatur zumeist genannt?

A Out-of-Focus-Miss

B Task-dependend Perceptual Blockage

C Inattentional Blindness

\section{Der Buchstabe der richtigen Antwort ist}

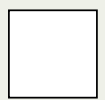

\section{Name}

Straße, Nr.

\section{PLZ, Ort}

Was ich noch sagen wollte ...

Coupon bitte ausfüllen und abschicken an

Springer Medizin Verlag $\mathrm{GmbH}$

Redaktion Im Focus Onkologie - Quiz 7-8/2017

Aschauer Straße 30, 81549 München

oder nehmen Sie online teil unter

www.springermedizin.de/im-focus-onkologie-quiz oder senden Sie uns eine E-Mail an kim.jene@springer.com oder senden Sie uns ein Fax an 089/20 304331113

Einsendeschluss: 08.09.2017

\section{Und das können Sie gewinnen ...}

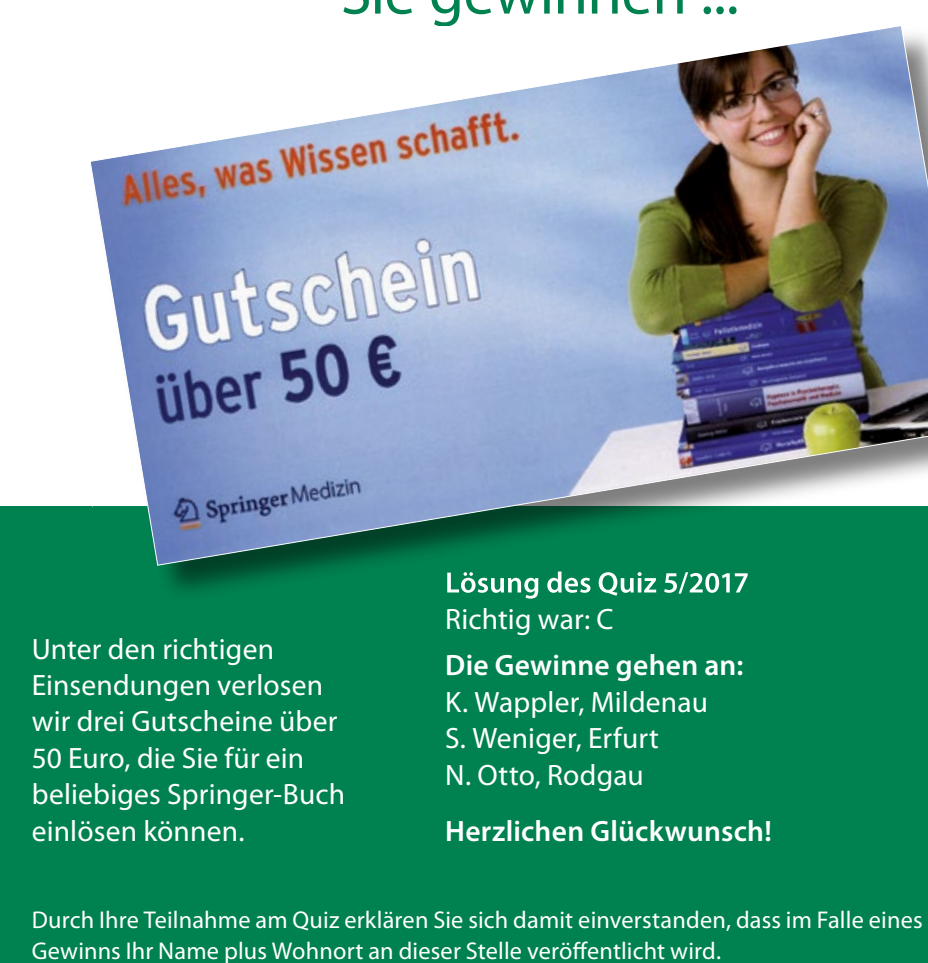

